\title{
Intrinsic Chemiluminescence Generation during Advanced Oxidation of Persistent Halogenated Aromatic Carcinogens
}

Li Mao, ${ }^{\dagger, \text { II }}$ Yu-Xiang Liu, ${ }^{\dagger, \text { II }}$ Chun-Hua Huang, ${ }^{\dagger}$ Hui-Ying Gao, ${ }^{\dagger}$ Balaraman Kalyanaraman, ${ }^{\dagger}$ and Ben-Zhan Zhu ${ }^{*},+$,

\author{
${ }^{\dagger}$ State Key Laboratory of Environmental Chemistry and Ecotoxicology, Research Center for Eco-Environmental Sciences, The \\ Chinese Academy of Sciences, Beijing, P. R. China 100085 \\ ${ }^{\ddagger}$ Biophysics Research Institute, Medical College of Wisconsin, Milwaukee, Wisconsin 53226, United States \\ ${ }^{\S}$ Linus Pauling Institute, Oregon State University, Corvallis, Oregon 97331, United States
}

\section{Supporting Information}

ABSTRACT: The ubiquitous distribution coupled with their carcinogenicity has raised public concerns on the potential risks to both human health and the ecosystem posed by the halogenated aromatic compounds (XAr). Recently, advanced oxidation processes (AOPs) have been increasingly favored as an "environmentally-green" technology for the remediation of such recalcitrant and highly toxic XAr. Here, we show that AOPs-mediated degradation of the priority pollutant pentachlorophenol and all other XAr produces an intrinsic chemiluminescence that directly depends on the generation of the extremely reactive hydroxyl radicals. We propose that the hydroxyl radical-dependent formation of quinoid intermediates and electronically excited carbonyl species is responsible for this unusual chemiluminescence production. A rapid, sensitive, simple, and effective chemiluminescence method was developed to quantify trace amounts of XAr and monitor their real-time degradation kinetics. These findings may have broad biological and environmental implications for future research on this important class of halogenated persistent organic pollutants.



PCP could be substituted by other
haloaromatics (XAr). X: $\mathrm{Cl}, \mathrm{F}, \mathrm{Br}, \mathrm{I}$.
•OH-generating
systems: $\left\{\begin{array}{l}\text { Fenton reaction } \\ \text { Fenton-like reaction } \\ \mathrm{O}_{3} \text { and } \mathrm{O}_{3} / \mathrm{H}_{2} \mathrm{O}_{2}\end{array}\right.$

Note: CL means chemiluminescence

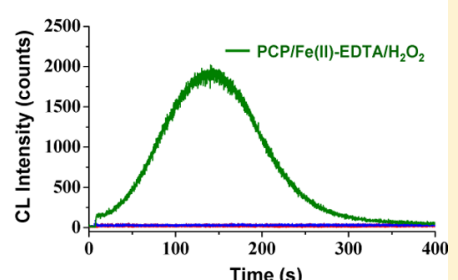

\section{INTRODUCTION}

Halogenated aromatic compounds (XAr) have been widely used as pesticides, herbicides, disinfectants, wood preservatives, personal care agents, pharmaceuticals, flame retardants, and many other industrial products. ${ }^{1-4}$ Most of these compounds are poorly biodegradable, both in water and soil. This makes them persistent and widely distributed in the environment, and has earned them the name persistent organic pollutants (POPs) from UNEP (United Nations Environment Programme). ${ }^{1-4}$ Their ubiquitous distribution coupled with their carcinogenicity has raised public concerns on the potential risks to both human health and the ecosystem posed by these recalcitrant and highly toxic XAr. ${ }^{3-13}$ Polyhalogenated phenols are an important class of XAr, and some of them, such as the widely used wood preservative pentachlorophenol (PCP) and 2,4,6-trichlorophenol, have been listed by the U.S. Environmental Protection Agency as priority pollutants. They are classified as group $2 \mathrm{~B}$ human carcinogens by the International Agency for Research on Cancer. ${ }^{1,2}$

Among all the techniques used or tested so far, advanced oxidation processes (AOPs) have been increasingly favored for treating recalcitrant PCP and other XAr in the remediation of contaminated water or soil. ${ }^{14-16}$ In these "environmentally 

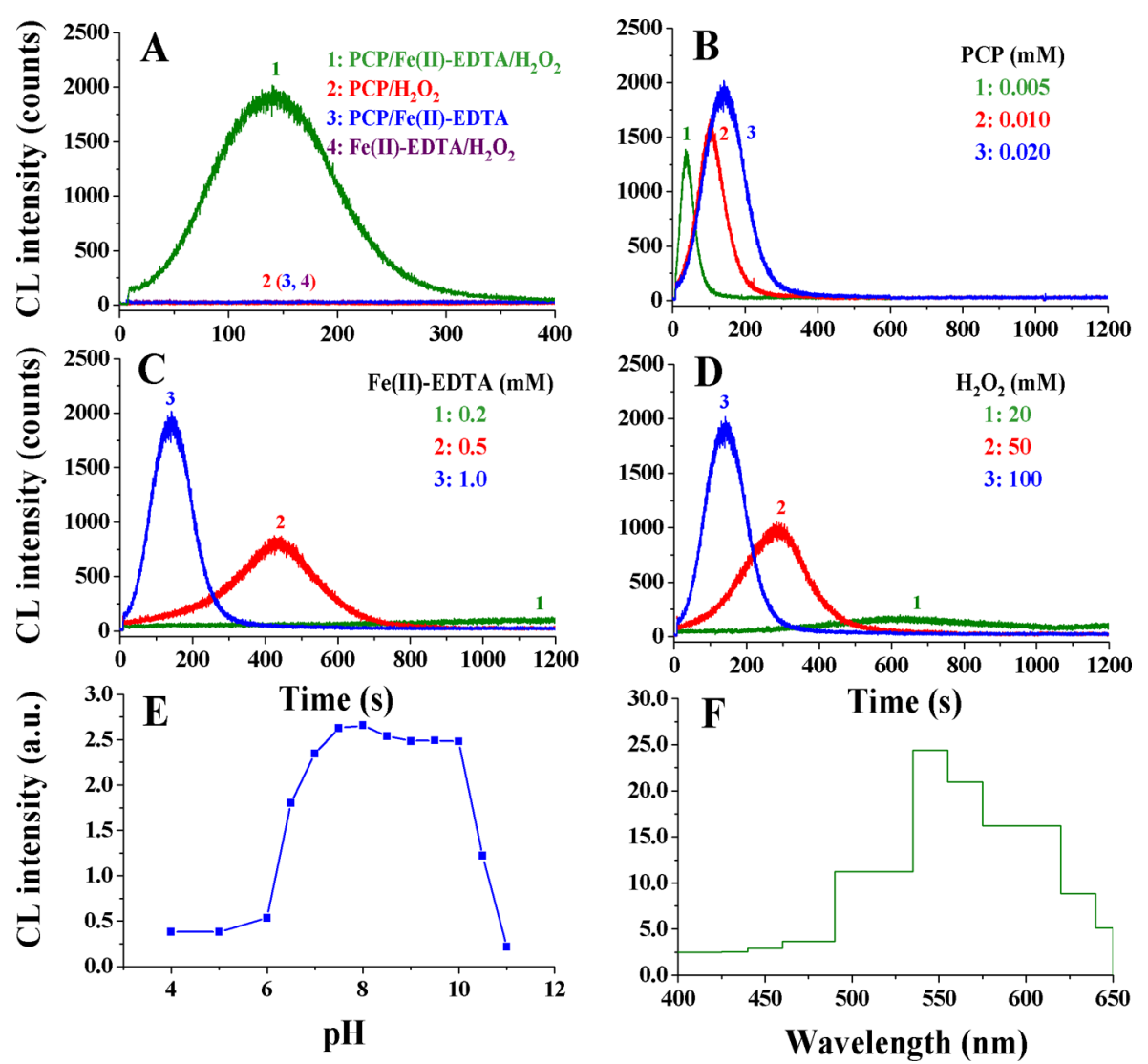

Figure 1. An intrinsic $\mathrm{CL}$ emission could be produced during advanced oxidation of PCP by the classic ${ }^{\bullet} \mathrm{OH}$-generating Fenton system. (A) $\mathrm{CL}$ could be produced by PCP/Fe(II)-EDTA/ $\mathrm{H}_{2} \mathrm{O}_{2}$; effects of PCP (B), $\mathrm{Fe}(\mathrm{II})-\mathrm{EDTA}(\mathrm{C}), \mathrm{H}_{2} \mathrm{O}_{2}$ (D), and pH (E) on CL production; (F) emission spectrum of CL. PCP, $20 \mu \mathrm{M}$; Fe(II)-EDTA, $1 \mathrm{mM} ; \mathrm{H}_{2} \mathrm{O}_{2}, 100 \mathrm{mM}$; all reactions were carried out in chelex-pretreated phosphate buffer (0.1 M, $\mathrm{pH}$ 7.4) and at room temperature.

mechanism underlying this unusual $\mathrm{CL}$ production was proposed, and a rapid, sensitive, simple, but effective CLbased method was developed to not only detect and quantify trace amounts of XAr, but also to monitor their degradation kinetics.

\section{MATERIALS AND METHODS}

Chemiluminescence (CL) Analysis. The CL emission from the reaction between $\mathrm{XAr}$ and an ${ }^{\bullet} \mathrm{OH}$-generating system was measured by an ultraweak $\mathrm{CL}$ analyzer (Institute of Biophysics, Chinese Academy of Sciences, China) with a CR120 red-sensitive photomultiplier tube (PMT, Hamamatsu, Japan). The CL analyzer was operated in pulse mode, and the CL signal was recorded by a computer equipped with a dataacquisition interface. Data acquisition and treatment were performed with BPCL software. The $\mathrm{CL}$ emission spectrum of $\mathrm{PCP} / \mathrm{Fe}(\mathrm{II})-\mathrm{EDTA} / \mathrm{H}_{2} \mathrm{O}_{2}$ was obtained using a set of interference filters, with the wavelength from 400 to $640 \mathrm{~nm}$, which were placed between the sample cuvette and the photomultiplier tube. During the determination of the CL emission wavelength, appropriate corrections were applied for both spectral response of the photomultiplier tube and transmissivity of filters. However, the CL emission spectrum obtained from the CL analyzer could only provide an approximate range, therefore a spectrofluorometer (Varian) set at CL mode was used to obtain a continuous CL spectrum and get a more accurate maximum wavelength.

Kinetic Study of ${ }^{\circ} \mathrm{OH}$ Formation in ${ }^{\circ} \mathrm{OH}$-Generating Systems by both ESR and Fluorescent Methods. The kinetics of ${ }^{\bullet} \mathrm{OH}$ formation in Fenton, Fenton-like, and ozonation systems were monitored by both ESR with DMPO (5,5-dimethyl-1-pyrroline $\mathrm{N}$-oxide) as the spin trapping agent, and fluorescence with terephthalic acid (TPA) as an ${ }^{\circ} \mathrm{OH}$ probe. ${ }^{24}$ In Fenton and Fenton-like systems, the basic system consisted of $2 \mu \mathrm{M}$ PCP, $0.1 \mathrm{mM}$ Fenton or Fenton-like agents, $10 \mathrm{mM} \mathrm{H}_{2} \mathrm{O}_{2}, 4 \mathrm{mM}$ TPA for fluorescence study, or $100 \mathrm{mM}$ DMPO for ESR study, in $0.1 \mathrm{M}$ chelex-treated phosphate buffer ( $\mathrm{pH} 7.4)$ at room temperature. For the ozonation system, no Fenton or Fenton-like agents were added. ESR spectra were recorded either immediately after the interaction of PCP with $\mathrm{Fe}(\mathrm{II})-\mathrm{EDTA}$ and $\mathrm{H}_{2} \mathrm{O}_{2}$, or at indicated time intervals on a Bruker ER 200 D-SRC spectrometer operating at $9.8 \mathrm{GHz}$. Fluorescence detection was performed on a Cary Eclipse (Varian) spectrofluorometer. Samples with TPA as the ${ }^{\bullet} \mathrm{OH}$ probe were excited at $312 \mathrm{~nm}$, and the resulting fluorescence was measured at $425 \mathrm{~nm}$.

Quantitative Detection of Several Typical Classes of XAr by the ${ }^{\circ} \mathrm{OH}$-Dependent $\mathrm{CL}$ Method Developed in This Study. The classic Fenton system was selected as the - OH-generating system. The solutions of $\mathrm{Fe}$ (II) (ammonium ferrous sulfate) and EDTA were mixed just before the CL experiment and stored under argon. The typical $\mathrm{XAr}$ were dissolved in diluted $\mathrm{NaOH}, \mathrm{CH}_{3} \mathrm{CN}$, or DMF solution. $\mathrm{H}_{2} \mathrm{O}_{2}$ and $\mathrm{XAr}$ were added into phosphate buffer in advance, and the CL measurements were started by the injection of $\mathrm{Fe}(\mathrm{II})-$ EDTA. The total intensity of CL in the whole spectra range was integrated during the whole $\mathrm{CL}$ process. To determine the linear concentration range, 16 different concentrations of XAr 



Figure 2. The CL production from $\mathrm{PCP} / \mathrm{Fe}(\mathrm{II})-\mathrm{EDTA} / \mathrm{H}_{2} \mathrm{O}_{2}$ was directly dependent on ${ }^{\bullet} \mathrm{OH}$ generation. (A) $\mathrm{CL}$ production from $\mathrm{PCP} / \mathrm{Fe}(\mathrm{II})-$ EDTA $/ \mathrm{H}_{2} \mathrm{O}_{2}$ could be markedly quenched by the typical ${ }^{\circ} \mathrm{OH}$ scavenger DMSO: PCP, $20 \mu \mathrm{M}$; Fe(II)-EDTA, $1 \mathrm{mM}$; $\mathrm{H}_{2} \mathrm{O}_{2}, 100 \mathrm{mM}$; DMSO, $1 \%$. (B) $\mathrm{CL}$ production was also observed with two other well-known ${ }^{\bullet} \mathrm{OH}$-generating Fenton agents $\mathrm{Fe}(\mathrm{II})-\mathrm{DTPA}$ and $\mathrm{Fe}$ (II)-NTA: PCP, $20 \mu \mathrm{M}$; $\mathrm{Fe}$ (II) complexes, $1 \mathrm{mM} ; \mathrm{H}_{2} \mathrm{O}_{2}, 100 \mathrm{mM}$. (C,D) Fluorescent and ESR kinetic study on ${ }^{\bullet} \mathrm{OH}$ generation by the three $\mathrm{Fe}(\mathrm{II})$ complexes and $\mathrm{H}_{2} \mathrm{O}_{2}$ : PCP, $2 \mu \mathrm{M}$; Fe(II) complexes, $0.1 \mathrm{mM} ; \mathrm{H}_{2} \mathrm{O}_{2}, 10 \mathrm{mM}$; TPA, $4 \mathrm{mM}$; DMPO, $100 \mathrm{mM}$; (E,F) CL could also be produced when PCP was treated with other ${ }^{\bullet} \mathrm{OH}$-generating systems including Fenton-like and ozonation systems. For Fenton-like systems: PCP, $20 \mu \mathrm{M}$; Fe(II)-EDTA, Co(II)EDTA, V(IV)-EDTA, Cr(III)-EDTA, $1 \mathrm{mM} ; \mathrm{H}_{2} \mathrm{O}_{2}, 100 \mathrm{mM}$. For ozonation systems, phosphate buffer was purged with $\mathrm{O}_{3}$ for $60 \mathrm{~s}$ before reaction, and then PCP (or PCP with $\mathrm{H}_{2} \mathrm{O}_{2}$ ) was quickly introduced into the reaction mixtures: PCP, $100 \mu \mathrm{M} ; \mathrm{H}_{2} \mathrm{O}_{2}, 100 \mathrm{mM}$. (G,H) Fluorescent kinetic study on ${ }^{\circ} \mathrm{OH}$ generation by Fenton-like and ozonation systems. For Fenton-like systems: PCP, $2 \mu \mathrm{M}$; Fenton-like agents, $0.1 \mathrm{mM} ; \mathrm{H}_{2} \mathrm{O}_{2}, 10$ $\mathrm{mM}$; TPA, $4 \mathrm{mM}$. For ozonation systems: PCP, $100 \mu \mathrm{M} ; \mathrm{H}_{2} \mathrm{O}_{2}, 100 \mathrm{mM}$; TPA, $4 \mathrm{mM}$. All reactions were carried out in chelex-pretreated phosphate buffer (0.1 M, pH 7.4) and at room temperature. Co(II), cobalt(II); V(IV), vanadium(IV); Cr(III), chromium(III).

covering six orders of magnitude were selected. They were $0.003,0.007,0.01,0.03,0.07,0.1,0.3,0.7,1.0,3.0,7.0,10,30$, 70, 100, and $300 \mu \mathrm{M}$.

\section{RESULTS AND DISCUSSION}

Production of Intrinsic CL Emission during Advanced Oxidation of PCP by the Classic ${ }^{\circ} \mathrm{OH}-$ Generating Fenton System. During our study of the advanced oxidation of PCP, we observed an intrinsic CL emission produced during the oxidation of PCP by the classic Fenton system (Fe(II)-EDTA and $\mathrm{H}_{2} \mathrm{O}_{2}$ ) in the absence of any chemiluminescent or fluorescent agents (Figure 1A). In contrast, neither the three individual components alone, nor the combination of any two components, could produce any CL. The intensity of CL was found to depend on the concentration of PCP, Fe(II)-EDTA, and $\mathrm{H}_{2} \mathrm{O}_{2}$; the higher is the concentration of any of the three components, the stronger is the $\mathrm{CL}$ (Figure $1 \mathrm{~B}-\mathrm{D}$ ). The $\mathrm{CL}$ was also found to depend on the $\mathrm{pH}$ of the buffer. Thus, no $\mathrm{CL}$ was observed at $\mathrm{pH} \leq 5$, but $\mathrm{CL}$ increased progressively with $\mathrm{pH}$ in the range of 5 to 8 , remained steady between $\mathrm{pH} 8$ and 10 , and then declined at $\mathrm{pH}>10$ (Figure 1E). The CL emission spectrum is characterized by a broad band $(510-580 \mathrm{~nm})$, which is centered at $535 \mathrm{~nm}$ (Figure $1 \mathrm{~F}$ and Supporting Information Figure S1). It is worth noting that CL could be also generated from horseradish peroxidase (HRP) catalyzed decomposition of chlorophenol in the presence of $\mathrm{H}_{2} \mathrm{O}_{2}$. 
Scheme 1. Proposed Molecular Mechanism for ${ }^{\bullet} \mathrm{OH}-$ Dependent CL Production by PCP/Fe(II) $-\mathrm{EDTA} / \mathrm{H}_{2} \mathrm{O}_{2}$

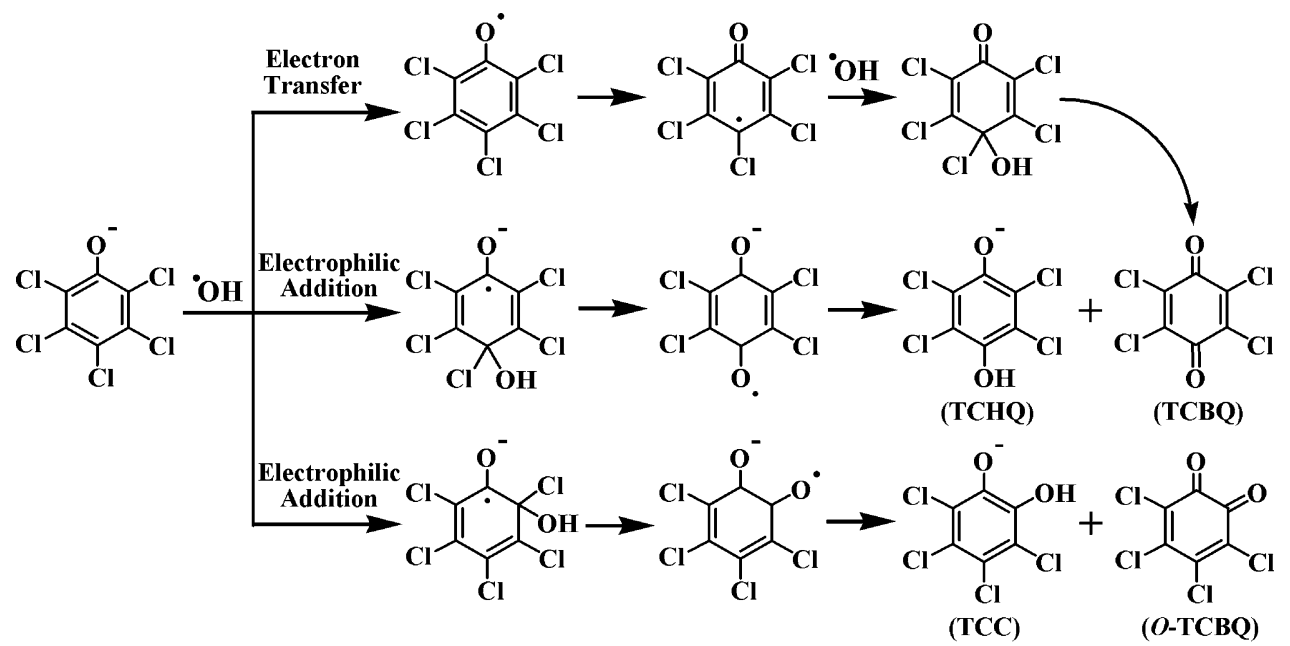





Direct Dependence of $\mathrm{CL}$ Production from $\mathrm{PCP} /$ $\mathrm{Fe}(\mathrm{II})-\mathrm{EDTA} / \mathrm{H}_{2} \mathrm{O}_{2}$ on ${ }^{\circ} \mathrm{OH}$ Generation. Since ${ }^{\circ} \mathrm{OH}$ is known to be produced by the classic Fenton system, we investigated whether or not the $\mathrm{CL}$ emission from $\mathrm{PCP} /$ $\mathrm{Fe}(\mathrm{II})-\mathrm{EDTA} / \mathrm{H}_{2} \mathrm{O}_{2}$ is dependent on ${ }^{\circ} \mathrm{OH}$ formation. Indeed, we found that the $\mathrm{CL}$ production by $\mathrm{PCP} / \mathrm{Fe}(\mathrm{II})-\mathrm{EDTA} /$ $\mathrm{H}_{2} \mathrm{O}_{2}$ was directly dependent on ${ }^{\bullet} \mathrm{OH}$ formation, as indicated by the following lines of evidence: (1) The CL produced by $\mathrm{PCP} / \mathrm{Fe}(\mathrm{II})-\mathrm{EDTA} / \mathrm{H}_{2} \mathrm{O}_{2}$ was markedly inhibited by several typical ${ }^{\bullet} \mathrm{OH}$ scavengers, such as dimethyl sulfoxide (DMSO), ethanol, and benzoate (Figure 2A and Supporting Information Figure S2); (2) not only the $\mathrm{CL}$ reaction and ${ }^{\circ} \mathrm{OH}$-generation could be markedly accelerated, but also the CL intensity and - $\mathrm{OH}$ yield were enhanced significantly as the concentration of $\mathrm{Fe}(\mathrm{II})-\mathrm{EDTA}$ and $\mathrm{H}_{2} \mathrm{O}_{2}$ was increased (Figure 1C,D); (3) CL was also observed when $\mathrm{Fe}$ (II)-EDTA was substituted by two other well-known ${ }^{\bullet} \mathrm{OH}$-generating Fenton agents $\mathrm{Fe}(\mathrm{II})-$ DTPA (diethylenetriaminepentaacetic acid) and Fe(II)-NTA (nitrilotriacetic acid) (Figure $2 \mathrm{~B}) ;^{26,27}$ and (4) CL emission correlated strongly with the rate of ${ }^{\bullet} \mathrm{OH}$ generation from the three $\mathrm{Fe}(\mathrm{II})$ complexes and $\mathrm{H}_{2} \mathrm{O}_{2}$, as measured by both ESR spin-trapping and fluorescent methods (Figure 2C,D).

$\mathrm{CL}$ Produced by PCP with Other ${ }^{\circ} \mathrm{OH}-$ Generating Fenton-like and Ozonation Systems. We found that CL could be produced not only with the classic Fe(II)-mediated Fenton systems, but also with other redox-active metalmediated Fenton-like systems including cobalt(II)-EDTA/ $\mathrm{H}_{2} \mathrm{O}_{2}$, vanadium(IV)-EDTA $/ \mathrm{H}_{2} \mathrm{O}_{2}$, and chromium(III)EDTA/ $\mathrm{H}_{2} \mathrm{O}_{2}$ (Figure $2 \mathrm{E}$ ), as well as the well-known ozonation systems, including $\mathrm{O}_{3}$ and $\mathrm{O}_{3} / \mathrm{H}_{2} \mathrm{O}_{2}$ (Figure $2 \mathrm{~F}$ ). ${ }^{\circ} \mathrm{OH}$ was produced by all these systems (Figure $2 \mathrm{G}, \mathrm{H}$ ).

Chlorinated Quinoid Compounds and 2,3-Dichloromaleic Acid as the Major Transient Intermediates and
Ring-Opened Product, Respectively. The aforementioned results suggest that, in the $\mathrm{PCP} / \mathrm{Fe}(\mathrm{II})-\mathrm{EDTA} / \mathrm{H}_{2} \mathrm{O}_{2}$ system, the primary species responsible for $\mathrm{CL}$ emission are probably transient intermediates or final products of PCP during its degradation by ${ }^{\bullet} \mathrm{OH}$. These may include the corresponding tetrachloroquinoid compounds, such as tetrachlorohydroquinone (TCHQ), tetrachloro-1,4-benzoquinone (TCBQ), tetrachlorocatechol (TCC), and tetrachloro-1,2-benzoquinone $(O$ TCBQ $)^{6-8}$ as well as their hydroxylation products such as trichlorohydroxy-1,4-benzoquinone (TrCBQ-OH) and 2,5dichloro-3,6-dihydroxy-1,4-benzoquinone (DDBQ). ${ }^{28-31}$ Indeed, we found by HPLC analysis that five of these six transient quinoid intermediates were formed in the $\mathrm{PCP} /$ $\mathrm{Fe}(\mathrm{II})-\mathrm{EDTA} / \mathrm{H}_{2} \mathrm{O}_{2}$ system (Supporting Information, Figure S3). When reacted with $\mathrm{H}_{2} \mathrm{O}_{2}$, these tetrachloroquinoid compounds also produced weak CL that was greatly enhanced by the addition of $\mathrm{Fe}(\mathrm{II})$-EDTA (Supporting Information, Figure S4). Further studies showed that these quinoid intermediates could be further decomposed to several ringopened products. Specifically, the major products were identified as 2,3-dichloromaleic acid (DCMA) (maximum yield, $22.7 \%$ ) and $\mathrm{CO}_{2}$ (and/or CO) (about 83.6\% PCP can be mineralized to inorganic carbon after $2 \mathrm{~h}$ ) (Supporting Information, Figure S3).

Possible Molecular Mechanism for CL Production during ${ }^{\circ} \mathrm{OH}-$ Dependent PCP Degradation. The fact that the emission spectrum of the CL in the PCP/Fe(II)-EDTA/ $\mathrm{H}_{2} \mathrm{O}_{2}$ system is characterized by a broad band $(510-580 \mathrm{~nm})$ centered at $535 \mathrm{~nm}$ (Figure $1 \mathrm{~F}$ and Supporting Information, Figure S1) suggests that the emitting species is the electronically excited carbonyls. ${ }^{32}$ On the basis of the above results and our previous findings, ${ }^{29,31}$ we proposed the following molecular mechanism for ${ }^{\bullet} \mathrm{OH}$-dependent $\mathrm{CL}$ emission from PCP/ 



Figure 3. Detection and quantification of chlorinated phenols and other typical haloaromatics (XAr) by ${ }^{\bullet} \mathrm{OH}$-dependent $\mathrm{CL}$ method. (A) $\mathrm{CL}$ production by 19 chlorinated phenols and nonchlorinated phenols in the presence of $\mathrm{Fe}(\mathrm{II})-\mathrm{EDTA} / \mathrm{H}_{2} \mathrm{O}_{2}$. Chlorinated phenols (or nonchlorinated phenols), $10 \mu \mathrm{M} ; \mathrm{Fe}(\mathrm{II})-\mathrm{EDTA}, 1 \mathrm{mM} ; \mathrm{H}_{2} \mathrm{O}_{2}, 100 \mathrm{mM}$; room temperature. (B) Standard curves of CL intensity and XAr concentrations; and (C) linear range and detection limit for several typical XAr as measured by the $\mathrm{CL}$ method developed in this study. All reaction mixtures contained $1 \mathrm{mM}$ $\mathrm{Fe}(\mathrm{II})-\mathrm{EDTA}$ and $100 \mathrm{mM} \mathrm{H}_{2} \mathrm{O}_{2}$, and reaction temperature was $37^{\circ} \mathrm{C}$. The reactions were carried out in chelex-pretreated phosphate buffer (0.1 $\mathrm{M}, \mathrm{pH}$ 7.4).

$\mathrm{Fe}(\mathrm{II})-\mathrm{EDTA} / \mathrm{H}_{2} \mathrm{O}_{2}$ (Scheme 1$):^{\bullet} \mathrm{OH}$ first attacks PCP, via electron transfer and/or electrophilic addition, forming pentachlorophenoxyl radical and tetrachlorosemiquinone radi$\mathrm{cal}^{6,33,34}$ which would further convert to the initial tetrachloroquinoid intermediates. The nucleophilic reaction may take place between these tetrachloroquinoid intermediates and $\mathrm{H}_{2} \mathrm{O}_{2}$, generating unusually highly energetic quinone-1,2dioxetanes in the presence of ${ }^{\circ} \mathrm{OH}$. These quinone-1,2dioxetanes further decompose to form the electronically excited carbonyl species [L]*. The CL at a broad band of 510-580 nm is emitted when the electronically excited state of $[\mathrm{L}] *$ returns to its ground state [L], and the subsequent decomposition of [L] leads to the formation of the final ring-opened products DCMA and $\mathrm{CO}_{2}$ (and/or CO).

It should be noted that neither the excited CL-emitting carbonyl species [L]* nor its ground state [L] could be detected under our current experimental conditions, which might be due to their unstable nature and extremely short lifespan. Further investigations are needed to detect and identify these species.

-OH-Dependent CL Production as a General Phenomenon for All XAr Tested. It is interesting to know whether CL could also be produced by other chlorinated phenols with the classic Fenton system; and if so, what is the structureactivity relationship? Indeed, we found that the analogous ${ }^{\bullet} \mathrm{OH}$ dependent CL emission could be observed when PCP was substituted with all of the 19 chlorinated phenol congeners (Supporting Information, Figure S5), while the nonhalogenated phenol and methylated phenol, such as $p$-cresol, generated only very low $C L$ under the same experimental conditions (Figure 3A and Supporting Information, Figure S6). The CL emission from the chlorinated phenols was found to depend not only on the chlorination level, but also on the chlorine substitution position, and each compound showed a distinct CL profile. In general, the higher is the chlorination level, the stronger is the $\mathrm{CL}$; however, there are clear exceptions. For example, the CL produced by PCP is weaker than that of 2,3,5,6-tetrachlorophenol (TeCP). Interestingly, the $\mathrm{CL}$ produced by chlorophenol isomers followed the general trend ortho > meta > para-substituted isomers. Furthermore, phenols with chlorine substitutions on both ortho- and meta-positions showed the highest CL emission. Thus, 2,5-dichlorophenol (DCP), 2,3,5trichlorophenol (TCP), and 2,3,5,6-tetrachlorophenol (TeCP) produced the highest $\mathrm{CL}$ emission among their corresponding DCP, TCP, and TeCP isomers.

More importantly, we found that, besides chlorinated phenols, CL could also be produced by all other halogenated phenols, such as pentabromophenol (PBP), pentafluorophenol (PFP), the flame retardant 3,3',5,5'-tetrabromobisphenol A (TBBPA), and the broad-spectrum antibacterial personal care agent triclosan (Supporting Information, Figures S7 and S8). In fact, CL could be observed with all XAr tested (see Supporting Information, Table S1, Figure S7 and S8). These include the widely used chlorophenoxyacetic acid herbicides, such as 2,4dichlorophenoxyacetic acid (2,4-D) and 2,4,5-trichlorophenoxyacetic acid $(2,4,5-\mathrm{T})$, which are the major components of Agent Orange; iodinated aromatic pharmaceuticals, such as thyroxine (T4) and triiodothyronine (T3); new chlorination disinfection haloquinoid byproducts in drinking water, such as 2,6-dichloro- and trichloro-1,4-benzoquinone (TrCBQ); ${ }^{35}$ halogenated naphthoquinone pesticides, such as 2,3-dichloro1,4-naphthoquinone (2,3-DCNQ); halogenated benzene biocides, such as pentachlorobenzene (PCB) and hexachlorobenzene; polyhalogenated diphenyl ether flame retardants, such as BDE 79 and BDE 209; polyhalogenated biphenyl dielectric and coolant fluids, such as trichlorobiphenyl (and their correspond- 

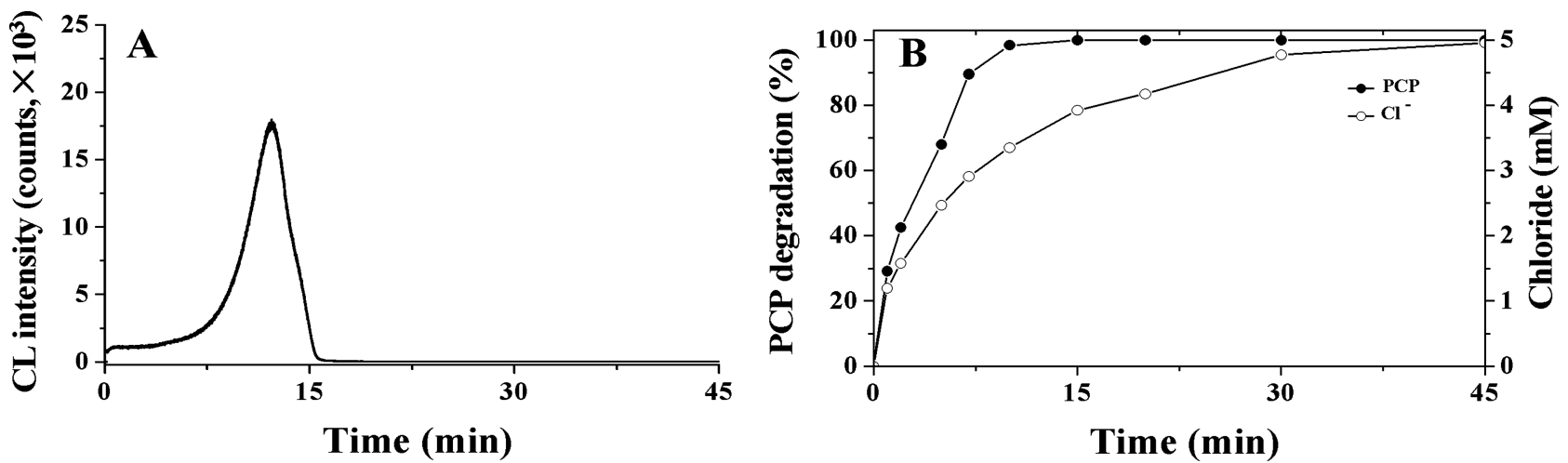

Figure 4. Good correlations were observed between CL emission (A) and degradation kinetics (B) during advanced oxidation of PCP. PCP, $1 \mathrm{mM}$; $\mathrm{Fe}(\mathrm{II})-\mathrm{EDTA}, 3 \mathrm{mM} ; \mathrm{H}_{2} \mathrm{O}_{2}, 300 \mathrm{mM}$. The reactions were carried out in chelex-pretreated phosphate buffer $(0.1 \mathrm{M}, \mathrm{pH} 7.4)$ and at room temperature.

ing diphenols and the quinones). These results indicate that $\bullet \mathrm{OH}$-dependent $\mathrm{CL}$ production during advanced oxidation is a general phenomenon for all XAr tested, but each compound exhibits a distinct CL emission profile.

Potential Biological/Environmental Implications and Possible Practical Applications. The fact that not only PCP and other halogenated phenols, but also all other tested XAr, could produce ${ }^{\circ} \mathrm{OH}$-dependent $\mathrm{CL}$ during their advanced oxidation may have interesting chemical, biological, environmental, pharmaceutical, and toxicological implications. Many widely used XAr, which are considered persistent organic pollutants (POPs) and probable human carcinogens, including polyhalogenated phenols (such as PCP, triclosan, and 3,3',5,5'tetrabromobisphenol A), Agent Orange, hexachlorobenzene, and diphenyl ether flame retardants, can be degraded, detoxified, and mineralized in various ${ }^{\bullet} \mathrm{OH}$-mediated AOPs. ${ }^{9-13}$ Recently, polychlorinated quinoid carcinogens were also identified as new chlorination disinfection byproducts in drinking water ${ }^{35}$ and found in discharges from pulp and paper mills. ${ }^{1,2}$ These XAr not only cause oxidative damage to DNA and other macromolecules, they also form protein and DNA adducts both in vitro and in vivo ${ }^{36-39}$ and therefore, are potentially carcinogenic toward mammalian organisms. Consequently, it is important to detect and measure these ubiquitous polyhalogenated pollutants or pharmaceutics both in the environment and in biological systems. It is well-known that CL-based analytical methods are inherently sensitive due to the relative ease with which low light emission can be quantified by photon-counting techniques. Therefore, we might use the CL-producing property to detect and measure trace amounts of several typical model XAr, including PCP, triclosan, 3,3',5,5'-tetrabromobisphenol A, TrCBQ 2,3-DCNQ PCB, 2,4-D, 2,4,5-T, T3, and T4 (see Materials and Methods, Figure 3B,C, and Supporting Information, Figure S8 and Tabels S1 and S2). Indeed, we found that as low as $1.8 \mathrm{ppb}$ of PCP could be detected by this novel CL assay, and the linear range for PCP is $2.6-18620 \mathrm{ppb}$ (Figure 3C). This is lower than the PCP concentration level of $40 \mathrm{ppb}$ found in the body fluids of people who are not occupationally exposed to PCP, and much lower than the level of $19580 \mathrm{ppb}$ in the occupationally exposed individuals. ${ }^{1}$ Because of the low PCP detection limit, this CL-based method might be used to measure PCP both in our environment and in biological systems.

To test whether the CL-based method can be applied to detect and measure possible XAr present in real environmental samples, the discharge from a paper mill was evaluated. We found that $\mathrm{CL}$ could be produced from the paper-mill discharge in the presence of $\mathrm{Fe}(\mathrm{II})-\mathrm{EDTA} / \mathrm{H}_{2} \mathrm{O}_{2}$ (Supporting Information, Figure S9), and further investigation indicated that the discharge indeed contained several XAr, including 4-chlorophenol, 2,4-dichlorophenol, and other chlorinated aromatics identified by GC-MS analysis coupled with enrichment through solid phase extraction (SPE). These results suggest that the CL-based method could be used to evaluate potential XAr contamination in real environmental samples.

Haloaromatics are degraded and detoxified during AOPs to low-toxic small molecules or even mineralized to $\mathrm{CO}_{2}$ or $\mathrm{CO}$. Therefore, during the practical remediation process, the kinetics of XAr degradation is often monitored to evaluate the efficiency of the remediation techniques. The traditional method, such as HPLC, ${ }^{9-11,33,40}$ used to monitor the kinetics of XAr degradation during AOPs is not only relatively time-consuming, but also consumes large amounts of solvents. Thus, a rapid, sensitive, simple, and effective method to monitor the degradation kinetics of XAr is urgently needed.

We found that the new CL-based method we developed in this study could also be used for this purpose. In the PCP/ $\mathrm{Fe}(\mathrm{II})-\mathrm{EDTA} / \mathrm{H}_{2} \mathrm{O}_{2}$ system, we found that the CL kinetics correlate well with the degradation kinetic curves of PCP as measured by HPLC. The time course of CL emission was accompanied concurrently with the degradation of PCP, and when the degradation level of PCP and the chlorine ions released reached the maximum, no further CL emission could be observed (Figure 4 and Supporting Information, Figure S10).

Another potential application for the CL-based method is to detect ${ }^{\bullet} \mathrm{OH}$ production when coupled with typical ${ }^{\bullet} \mathrm{OH}$ scavenging agents since the $\mathrm{CL}$ produced by ${ }^{\circ} \mathrm{OH}$-generating systems with XAr was found to be directly and specifically dependent on ${ }^{\bullet} \mathrm{OH}$ production, but not on other reactive oxygen species, such as superoxide anion radical and singlet oxygen.

Distinguishing Characteristics and Advantages of This Novel CL-Dependent Method. When compared with previously reported analytical methods of measuring XAr, this novel CL-dependent method showed the following characteristics and advantages: (1) It is sensitive and selective since high intensity CL emission is observed from XAr, and each showed a distinct CL profile, while no or only extremely weak CL was obtained from nonhalogenated aromatics. (2) The CL emission 
produced by XAr and an ${ }^{\bullet} \mathrm{OH}$-generating system is a direct and intrinsic CL, so no other fluorescent or chemiluminescent agents are needed. (3) It is simple and rapid to operate, and does not require time-consuming derivatization and sample pretreatment. (4) The chemical agents and the portable CL instrument used are quite inexpensive and also readily available commercially. Therefore, when compared to other methods, this CL-based method could reduce cost and would be very suitable for practical applications, especially on-site monitoring and analysis. (5) It could be used not only to detect and measure trace amounts of XAr in both pure and real samples, but also to monitor their real-time degradation kinetics, especially during advanced oxidation processes.

\section{ASSOCIATED CONTENT}

\section{S Supporting Information}

Experimental details; supporting figures. The Supporting Information is available free of charge on the ACS Publications website at DOI: 10.1021 /acs.est.5b01227.

\section{AUTHOR INFORMATION}

\section{Corresponding Author}

*Phone: +86-10-62849030; fax: +86-10-62923563; e-mail: bzhu@rcees.ac.cn.

\section{Author Contributions}

${ }^{\mathrm{I}}$ L.M. and Y.-X.L. contributed equally to this work.

\section{Notes}

The authors declare no competing financial interest.

\section{ACKNOWLEDGMENTS}

The work in this paper was supported by the Strategic Priority Research Program of CAS Grant No. XDB01020300; NSF China Grants (21207139, 21477139, 21237005 and 21321004); and NIH Grants (ES11497, RR01008 and ES00210).

\section{REFERENCES}

(1) Zhu, B. Z.; Shan, G. Q. Potential mechanism for pentachlorophenol-induced carcinogenicity: A novel mechanism for metalindependent production of hydroxyl radicals. Chem. Res. Toxicol. 2009, 22, 969-977.

(2) Zhu, B. Z.; Zhu, J. G.; Fan, R. M.; Mao, L. Metal-independent pathways of chlorinated phenol/quinone toxicity. Adv. Mol. Toxicol. 2011, 5, 1-43.

(3) Dann, A. B.; Hontela, A. Triclosan: Environmental exposure, toxicity and mechanisms of action. J. Appl. Toxicol. 2010, 31, 285-311.

(4) De Wit, C. A. An overview of brominated flame retardants in the environmental. Chemosphere 2002, 46, 583-624.

(5) Ramamoorthy, S. Chlorinated Organic Compounds in the Environment: Regulatory and Monitoring Assessment; CRC Press: Boca Raton, FL, 1997.

(6) Fang, X. W.; Schuchmann, H. P.; von Sonntag, C. The reaction of the $\mathrm{OH}$ radical with pentafluoro-, pentachloro-, pentabromo- and 2,4,6-triiodophenol in water: Electron transfer vs addition to the ring. J. Chem. Soc., Perkin Trans. 2000, 2, 1391-1398.

(7) Zimbron, J. A.; Reardon, K. F. Fenton's oxidation of pentachlorophenol. Water Res. 2009, 43, 1831-1840.

(8) Lan, Q.; Li, F.; Liu, C.; Li, X. Z. Heterogeneous photodegradation of pentachlorophenol with maghemite and oxalate under UV illumination. Environ. Sci. Technol. 2008, 42, 7918-7923.

(9) Gupta, S. S.; Stadler, M.; Noser, C. A.; Ghosh, A.; Steinhoff, B.; Lenoir, D.; Horwitz, C. P.; Schramm, K. W.; Collins, T. J. Rapid total destruction of chlorophenols by activated hydrogen peroxide. Science. 2002, 296, 326-328.
(10) Sorokin, A.; Seris, J. L.; Meunier, B. Efficient oxidative dechlorination and aromatic ring-cleavage of chlorinated phenols catalyzed by iron sulfophthalocyanine. Science. 1995, 268, 1163-1166.

(11) Zhang, H.; Huang, C. H. Oxidative transformation of triclosan and chlorophene by manganese oxides. Environ. Sci. Technol. 2003, 37, 2421-2430.

(12) Zhong, Y. H.; Liang, X.; Zhong, Y.; Zhu, J.; Zhu, S.; Yuan, P.; He, H.; Zhang, J. Heterogeneous UV/Fenton degradation of TBBPA catalyzed by titanomagnetite: Catalyst characterization, performance and degradation products. Water Res. 2012, 46, 4633-4644.

(13) Peller, J.; Wiest, O.; Kamat, P. V. Mechanism of hydroxyl radical-induced breakdown of the herbicide 2,4-dichlorophenoxyacetic acid (2,4-D). Chem.-Eur. J. 2003, 9, 5379-5387.

(14) Von Sonntag, C. Advanced oxidation process: Mechanistic aspects. Water. Sci. Technol. 2008, 58, 1015-1021.

(15) Wang, J. N.; Xu, L. J. Advanced oxidation processes for wastewater treatment: Formation of hydroxyl radical and application. Crit. Rev. Environ. Sci. Technol. 2012, 42, 251-325.

(16) Pera-Titus, M.; García-Molina, V.; Baños, M. A.; Giménez, J.; Esplugas, S. Degradation of chlorophenols by means of advanced oxidation processes: a general review. Appl. Catal. B: Environ. 2004, 47, $219-256$.

(17) Schuster, G. B. Chemiluminescence of organic peroxides. Conversion of ground-state reactants to excited-state products by the chemically initiated electron-exchange luminescence mechanism. Acc. Chem. Res. 1979, 12, 366-373.

(18) Matsumoto, M. Advanced chemistry of dioxetane-based chemiluminescent substrates originating from bioluminescence. $J$. Photochem. Photobiol. C 2004, 5, 27-53.

(19) Almeida de Oliveira, M.; Bartoloni, F. H.; Augusto, F. A.; Ciscato, L. F.; Bastos, E. L.; Baader, W. J. Revision of singlet quantum yields in the catalyzed decomposition of cyclic peroxides. J. Org. Chem. 2012, 77, 10537-10544.

(20) Widder, E. A. Bioluminescence in the ocean: Origins of biological, chemical, and ecological diversity. Science. 2010, 328, 704708 .

(21) Adam, W.; Kazakov, D. V.; Kazakov, V. P. Singlet-oxygen chemiluminescence in peroxide reactions. Chem. Rev. 2005, 105, 3371-3387.

(22) Grayeski, M. L. Chemiluminescence analysis. Anal, Chem. 1987, 59, 1243A-1256A.

(23) McCapra, F. Chemical generation of excited states: The basis of chemiluminescence and bioluminescence. Methods Enzymol. 2000, 305, 3-47.

(24) Barreto, J. C.; Smith, G. S.; Strobel, N. H.; Mcquillin, P. A.; Miller, T. A. Terephthalic acid: A dosimeter for the detection of hydroxyl radicals in vitro. Life Sci. 1995, 56, PL89-96.

(25) Badder, W. J.; Gillo, V. E. Peroxidase-catalysed chlorophyll destruction accompanied by the formation of electronically excited states: chlorophyll emission not due to energy transfer from excited substrate metabolites. J. Photochem. Photobiol., A 1996, 101, 49-55.

(26) Wardman, P.; Candeias, L. P. Fenton chemistry: An introduction. Radiat. Res. 1996, 145, 523-531.

(27) Goldstein, S.; Meyerstein, D.; Czapski, G. The Fenton reagents. Free Radic. Biol. Med. 1993, 15, 435-445.

(28) Zhu, B. Z.; Zhao, H. T.; Kalyanaraman, B.; Liu, J.; Shan, G. Q.; $\mathrm{Du}, \mathrm{Y}$. G.; Frei, B. Mechanism of metal-independent decomposition of organic hydroperoxides and formation of alkoxyl radicals by halogenated quinones. Proc. Natl. Acad. Sci. U.S.A. 2007, 104, 36983702.

(29) Zhu, B. Z.; Kalyanaraman, B.; Jiang, G. B. Molecular mechanism for metal-independent production of hydroxyl radicals by hydrogen peroxide and halogenated quinones. Proc. Natl. Acad. Sci. U. S. A. 2007, 104, 17575-17578.

(30) Zhu, B. Z.; Shan, G. Q.; Huang, C. H.; Kalyanaraman, B.; Mao, L.; Du, Y. G. Metal-independent decomposition of hydroperoxides by halogenated quinones: Detection and identification of a quinone ketoxy radical. Proc. Natl. Acad. Sci. U.S.A. 2009, 106, 11466-11471. 
(31) Zhu, B. Z.; Mao, L.; Huang, C. H.; Qin, H.; Fan, R. M.; Kalyanaraman, B.; Zhu, J. G. Unprecedented hydroxyl radicaldependent two-step chemiluminescence production by polyhalogenated quinoid carcinogens and $\mathrm{H}_{2} \mathrm{O}_{2}$. Proc. Natl. Acad. Sci. U.S.A. 2012, 109, 16046-16051.

(32) Brunmark, A.; Cadenas, E. Electronically excited state generation during the reaction of $p$-benzoquinone with $\mathrm{H}_{2} \mathrm{O}_{2}$. Free. Radic. Biol. Med. 1987, 3, 169-180.

(33) Weavers, L. K.; Malmstadt, N.; Hoffmann, M. R. Kinetics and mechanism of pentachlorophenol degradation by sonication, ozonation, and sonolytic ozonation. Environ. Sci. Technol. 2000, 34, 12801285.

(34) Fukushima, M.; Tatsumi, K. Degradation pathways of pentachlorophenol by photo-Fenton systems in the presence of iron(III), humic acid and hydrogen peroxide. Environ. Sci. Technol. 2001, 35, 1771-1778.

(35) Zhao, Y. L.; Qin, F.; Boyd, J. M.; Anichina, J.; Li, X. F. Characterization and determination of chloro- and bromo-benzoquinones as new chlorination disinfection byproducts in drinking water. Anal. Chem. 2010, 82, 4599-4605.

(36) Song, Y.; Wagner, B. A.; Witmer, J. R.; Lehmler, H. J.; Buettner, G. R. Nonenzymatic displacement of chlorine and formation of free radicals upon the reaction of glutathione with $\mathrm{PCB}$ quinones. Proc. Natl. Acad. Sci. U. S. A. 2009, 106, 9725-9730.

(37) Chignell, C. F.; Han, S. K.; Mouithys-Mickalad, A.; Sik, R. H.; Stadler, K.; Kadiiska, M. B. EPR studies of in vivo radical production by $3,3^{\prime}, 5,5^{\prime}$-tetrabromobisphenol A (TBBPA) in the Sprague-Dawley rat. Toxicol. Appl. Pharmacol. 2008, 230, 17-22.

(38) Teuten, E. L.; Xu, L.; Reddy, C. M. Two abundant bioaccumulated halogenated compounds are natural products. Science 2005, 307, 917-920.

(39) Kelly, B. C.; Ikonomou, M. G.; Blair, J. D.; Morin, A. E.; Gobas, F. A. P. C. Food web-specific biomagnification of persistent organic pollutants. Science. 2007, 317, 236-239.

(40) Sun, Y.; Pignatello, J. J. Photochemical reactions involved in the total mineralization of 2,4-D by $\mathrm{Fe}^{3+} / \mathrm{H}_{2} \mathrm{O}_{2} / \mathrm{UV}$. Environ. Sci. Technol. 1993, 27, 304-310. 